\title{
A non-randomized study investigating the effectiveness of cognitive reframing in socially disconnected widows
}

\author{
Victor Moses $\odot$
}

Department of Educational Psychology and Counselling, Ahmadu Bello University, Zaria, Nigeria

\section{ABSTRACT}

Objectives: Socially disconnected widows usually live a lonely and depressing life with anxiety and low selfworth. Many have contemplated suicide and others have become a victim of suicide already. Evolving an intervention to provide succor to them to take control of their lives may help a great deal. This paper presents the results of a nonrandomized study assessing the potency of cognitive reframing (CR) in reducing social disconnectedness (SD) among the widows.

Methods: The pre- and post-data was collected from a non-randomized sample of 41 widows in the treatment group and 45 in the waitlist control group. The mean age of the participants was $41.383 \pm 6.730$ [95\% CI = $39.940-42.940](\min .=25-\max .=56)$ years. The cognitive reframing administered spanned for eight weeks. Results: Analysis of the data collected suggests that cognitive reframing is significantly effective in reducing socially disconnected behavior among the widows in the study. The social disconnected behavior among the widows reduced by $40.95 \%$ compared to $8.29 \%$ observed in the waitlist control group.

Conclusions: The CR technique may be helpful in reducing social disconnectedness in widows. However, further study may be required in a randomized sample to enhance generalization.

Keywords: Social disconnectedness, widows, cognitive reframing

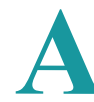

widow is a woman whose spouse has died. Losing a spouse to death through natural or manmade tragedy only brings pains, forcing many women into unprepared widowhood. All over the world, there are an estimated 258 million widows, with over 115 million living in poverty [1]. In Nigeria, male adult mortality increased from 25.98 in 1970 to 31.92 deaths per 100 male population aged $15-60$ in 2015 . The average annual death rate for adult male in Nigeria is $2.38 \%$ as of 2015 [2]. When a husband dies, typically, the world of a woman falls apart, and she has to dwell in a cruel world, full of misery and shame and abuses for the rest of her life. It brings a lot of negative impact on the health and well being of widows[3, 4]. Widow- hood has been described as one of the most stressful events in life $[5,6]$. The literature demonstrates that widowhood in old age is a dreaded phase of life due to its influence on health and well being [6-8].The plight of widows is one of the most important, yet under-reported issues facing the world today. For many women, becoming a widow does not just mean the heartache of losing a husband, but often losing everything else altogether. Through no fault of theirs, widows suffer stigma, violence, sometimes, as in parts of sub-Saharan Africa, being forced to "cleanse" herself by having sexual intercourse with a relative or a stranger or forced to marry the deceased relative [9]. Across the world, gender inequality remains the norm, 
and women have continued to encounter discriminatory practices as a result of religious and cultural practices [10]. In some parts of Africa and Nigeria, in particular, women are still treated as minors and sometimes as second-class citizens who are only to be seen and not to be heard $[11,12]$. The unjust treatment faced by widows has made many to suffer from various serious mental and physical health challenges.

as a social relationship is a fundamental and vital component of human life and has important impacts on health, many widows continue to suffer from social disconnectedness, which is associated with a wide variety of adverse health outcomes [13-15]. Specifically, the term "social disconnectedness" is not a diagnosis for a specific psychiatric disorder, but a phenomenon of social isolation and the pathology of introverted behavior. The former refers to the condition of staying in one's own house to avoid relationships with others, the latter means pathology due to some psychiatric disorders or personality of introversion [16]. It is also viewed as an individual's subjective experience of a lack of satisfying human relationships, usually accompanied by a negative feeling, causing distress to an individual. Socially disconnected people often experience a subjective sense of inner emptiness or hollowness, with feelings of separation or isolation from the world, and a woman grieving over the loss of her husband is not an exemption $[17,18]$. Although social support may buffer the effects of loneliness, mental problems such as depression, insomnia, and hallucinations of the dead, continue to live many widows in trouble. Widows arguably have lower levels of social support in Nigeria than married individuals do. One of the major effects of widowhood is poverty and emotional trauma. Many Nigerian widows are pauperized by those. Upon the death of a husband, widows may be completely dispossessed and chased off [19]. Widowhood among the women is simply a life of deprivation and it can have far-reaching consequences for mental well-being. In order to promote mental and general well-being and to alleviate loneliness and social disconnectedness among widows, intervention programs must be developed to improve existing or develop new relationships such as friendships [20-22].

Much research has been carried out examining the effectiveness of cognitive reframing (CR) in treating several mental problems [23-25]. CR is a psychological intervention that has to do with helping a client to identify and then dispute irrational or maladaptive thoughts. It's used to help clients to look at his condition from a slightly different perspective. The CR has proven to be an effective behavioral intervention used in modifying various psychological problems. Therefore, if this intervention could be used to assess the extent to which it can decrease socially disconnected behavior among the widows, it will be beneficial. Hawton et al. [26] suggested that practices could target people at risk of social disconnectedness, as individuals need to be identified early with interventions before the deterioration of their health or quality of life occurs. This study, therefore, used an on randomized method to investigate the effectiveness of cognitive reframing in socially disconnected widows in Nigeria.

\section{METHODS}

\section{Research Design}

The research is a quasi-experimental study involving two-group pre-test/posttest design (Fig.1) $[27,28]$. Using two groups in an experiment is helpful because it helps the researcher to assess the effectiveness of an intervention by comparing before and after the outcome of participants in both groups [29]. Usually, the intervention is considered effective when participants' outcome scores improve compared to baseline across the two groups [30].

\section{Participants}

The study population involves widows in Kaduna metropolis who had a high score on the Social disconnected ness Questionnaire. In the study area, there is no published report about the exact number of widows by local authorities. Widows, however, constitute a large proportion of all women. A 2015 world report estimate, shows the population of widows in Nigeria was put at over two million, 2,145,605 [1]. Van Voorhis and Morgan [31] and De Winter [32]

\begin{tabular}{|c|c|c|c|}
\hline GRP A & 01 & $X$ & 02 \\
\hline GRP B & 03 & & 04 \\
\hline
\end{tabular}

Fig.1. Proposed research design for the study (Interpretation: $01=$ Pretest, $X=$ Intervention, and $02=$ Posttest). 
recommended using a small sample size to ensure adequate attention to the participants and eliminate rowdiness and likelihood of attrition. In this study, sixty-four participants were used for the experimental and waitlist control group respectively. After the eightweek intervention, the study recorded a $35.93 \%$ and $29.68 \%$ attrition rate in both the treatment and waitlist control group. The final analysis was done with 41 participants in the treatment group and 45 in the control group. The following flowchart shows the sample size of the study and the sample recruitment procedure (Fig. 2).

\section{Ethical Consideration}

Participation in this research was voluntary. Only widows identified with the social disconnectedness behavior and have agreed to participate after signing a consent form, took part in the study. The consent form as attached to the questionnaire reads: "The essence of the study has been explained to me, and I have been given the opportunity to ask questions about this research. I understand the aims, duration of the intervention and have agreed to participate. I was also assured of the confidentiality of any information I gave. I understand that my participation is voluntary, so I can withdraw from the study at any time."
At the end of the study, the waitlist control group was introduced to the treatment and was given handout on how to use it at home [9].

\section{Treatment Credibility}

Two items from the Treatment Evaluation Questionnaire [33] were used to assess treatment credibility, and these items were completed at posttreatment. These items were chosen because they appeared less likely to be affected by treatment success or failure, though it remained possible that treatment response biased these findings [34]. Participants reported whether they felt the treatment was logical and reasonable and whether they would recommend the intervention to a friend with a similar problem. The items were measured on a Likert scale ranging from 0 (strongly disagree) to 5 (not sure) to 10 (strongly agree) [9].

\section{Outcome Measure}

The social disconnectedness questionnaire developed by Russell [35] was used to assess social disconnectedness among participants during the pretreatment and post-treatment phases. The Social isolation questionnaire includes 20 questions used to assess how lonely the respondent feels. Each question

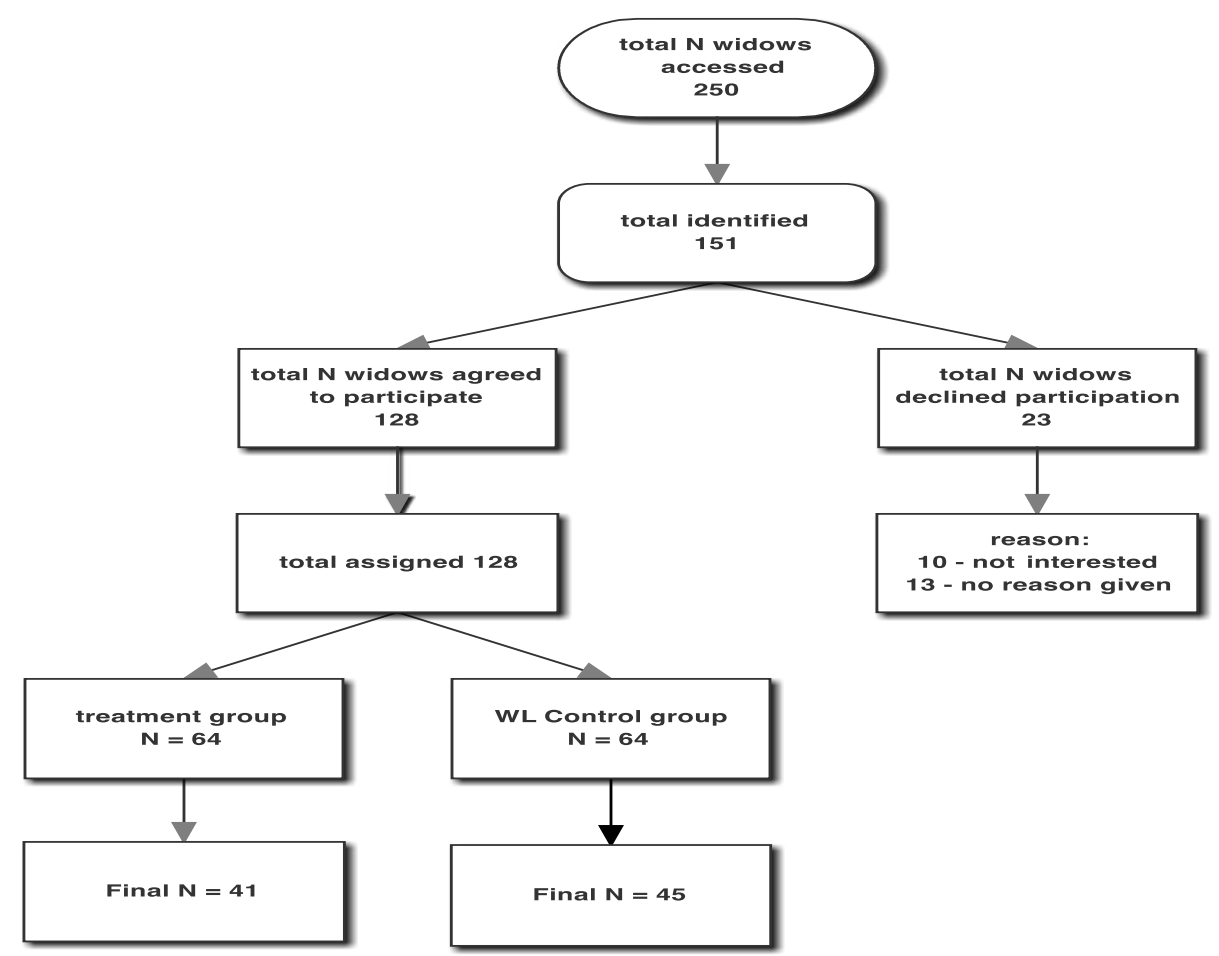

Fig.2. The sample size of the study. 
Table 1. Brief explanation of CR intervention for widows

\begin{tabular}{|c|c|c|}
\hline Sessions & Cognitive Reframing & Description \\
\hline Session One & Introduction and pretest/intake & $\begin{array}{l}\text { At this stage, the researcher introduces self to the } \\
\text { participants, explain the essence of the study, } \\
\text { sought for the consent and administer baseline test } \\
\text { using SDQ }\end{array}$ \\
\hline Session Two & $\begin{array}{l}\text { Identifying the upsetting } \\
\text { situation }\end{array}$ & $\begin{array}{c}\text { During this session, participants were given CCD } \\
\text { to fill. The essence was to identify upsetting } \\
\text { thoughts. }\end{array}$ \\
\hline Session Three & Recording negative feelings & $\begin{array}{l}\text { The researcher along with the participants record } \\
\text { identified upsetting/negative feelings }\end{array}$ \\
\hline Session Four & $\begin{array}{l}\text { Record and Analyze these } \\
\text { thoughts }\end{array}$ & $\begin{array}{l}\text { At this stage, the researcher works with the } \\
\text { participants to analyze in order to identify } \\
\text { prevalence negative and unbalance thoughts that } \\
\text { need to be countered }\end{array}$ \\
\hline Session Five & $\begin{array}{c}\text { Construct realistic and balanced } \\
\text { thoughts }\end{array}$ & $\begin{array}{l}\text { The participants were guided to countering } \\
\text { negative and unbalance thoughts to a more } \\
\text { realistic thought }\end{array}$ \\
\hline Session six & Continuation of session five & Same as session five \\
\hline Session Seven & $\begin{array}{l}\text { Evaluation of the reframing } \\
\text { process }\end{array}$ & $\begin{array}{c}\text { During this stage, participants were given a } \\
\text { checklist of cognitive distortion (CCD) developed } \\
\text { by Burns[42]to assess whether they have adopted } \\
\text { a more realistic and balance thoughts }\end{array}$ \\
\hline Session Eight & Posttest/termination & $\begin{array}{l}\text { The SDQ was administered for the last time to } \\
\text { examine if changes have occurred after the } \\
\text { intervention. The sessions also terminate here }\end{array}$ \\
\hline
\end{tabular}

begins with the statement "How often do you feel" followed by a positive or negative description of social interactions with others. The respondent is asked to indicate the frequency he/she feels that way (never $=$ 1 , rarely $=2$, sometimes $=3$, always $=4$ ) for each question. The instrument is suitable for respondents between the ages of 18 and above. Items 1, 5, 6, 9, 10, $15,16,19$, and 20 were scored in reverse. All scores were summed together with higher scores indicating greater degrees of isolation or disconnectedness [35]. The instrument was divided into sections. The first section was made up of demographic characteristics of the respondents (age, personal income, years of widowhood, number of children, and source of financial assistance), while the second section consists of statements used to assess the dependent variable (social disconnectedness). The social disconnectedness questionnaire produced a satisfactory reliability index and consistency, and it is one of the most commonly used instrument to assess social isolation behavior. The scale has an internal consistency of .89 to .94 and test-retest of .73 [35]. It has been used successfully in several countries of different cultures [36-38].

\section{Intervention}

The data collection procedure was discussed in three phases; pretreatment phase, treatment phase, and post-treatment phase (Table 1).

\section{Pretreatment Phase (week 1)}

During week 1, the researcher introduced himself to the volunteered research participants. The participants received a briefing on the essence of the study and filled consent form approving their voluntary participation in the study. We (researcher and two assistants) administered some questionnaire, which we used to measure widows' level of social disconnectedness. We used the data collected at this stage to serve as the pretest data and bases for inclusion to the study. Participants were directed on how to fill the instruments and after that, advance 
arrangements were made concerning further meetings [27].

\section{Treatment Phase (week 2-7)}

The treatment group received cognitive reframing (CR) from week 2-7. Twelve noon every Saturday was scheduled as the meeting time. The cognitive reframing used in this study were those guided by the work of Greenberger and Westbrook [39], Brosan and Hogan [40], and Gilbert [41]. The procedures were used with some modification to suit the need of the problem under investigation. Other researchers have used the techniques and procedures and they have shown to be effective in reducing mental healthrelated behavior problems. But there appears to be a dearth of researches using the technique in treating social disconnectedness among widows.

\section{Statistical Analysis}

The data collected were statistically analyzed with JMP ver. 13.2., computer software. The analysis was done using the Analysis of Covariance to test for treatment effects. ANCOVA is usually suitable when two or more groups are subjected to pre-test and posttest while the pre-test is treated as a covariate to 'control' for initial differences existing between the groups. Prior to testing the treatment effects, however, a test of assumption of homogeneity of regression slope was carried out. This analysis was done using an unequal number of participants from the experimental and control group due to attrition [27]. A 35.9\% and $23.4 \%$ attrition rate was recorded for the treatment group and waitlist control group respectively. A .05 standard of statistical significance for the decision was used in testing the treatment effect.

\section{RESULTS}

Table 2 showed that there is no significant difference between treatment and control group in term of educational attainment, $\chi^{2}=6.316, p=0.097$. The outcome indicates that $19.5 \%$ of the participants in the treatment group had no formal education as compared to the control group with only $4.4 \%$. There were $17(41.5 \%)$ of the participants in the experimental group who reported to have primary education compared to $22(48 \%)$ in the control group. Additionally, $12(29.3 \%)$ in the treatment had secondary education compared to a higher $19(42.2 \%)$ in the waitlist control group. Only 4 participants representing $9.8 \%$ of the total sample in the treatment group reached the tertiary level of education unlike 2 participants representing $4.4 \%$ in the control group.

About family size, having to do with the number of children, data analysis indicates that $10(24.4 \%)$ of the participants in the treatment group reported having 1-3 children compared to $5(11.1 \%)$ participants in the control group. Over $41 \%$ in the treatment group reported having $4-6$ kids compared to $33(73.3 \%)$ in

Table 2. A comparative descriptive statistic of the respondents by Group

\begin{tabular}{|c|c|c|c|c|c|c|c|}
\hline \multirow[t]{2}{*}{ Group } & \multirow{2}{*}{$\begin{array}{c}\text { Description } \\
\text { Education }\end{array}$} & \multicolumn{4}{|c|}{ Levels } & \multicolumn{2}{|c|}{ Statistic } \\
\hline & & $\begin{array}{l}\text { No formal } \\
\text { Education }\end{array}$ & $\begin{array}{c}\text { Primary } \\
\text { Education }\end{array}$ & $\begin{array}{l}\text { Secondary } \\
\text { Education }\end{array}$ & $\begin{array}{c}\text { Tertiary } \\
\text { Education }\end{array}$ & $\mathrm{Chi}^{2}$ & $p$ value \\
\hline 1 & & $8(19.5 \%)$ & $17(41.5 \%)$ & $12[29.3 \%]$ & $4(9.8 \%)$ & 6.316 & 0.097 \\
\hline 2 & & $2(4.4 \%)$ & $22(48.9 \%)$ & $19[42.2 \%]$ & $2(4.4 \%)$ & & \\
\hline & $\begin{array}{l}\text { Number of } \\
\text { Children }\end{array}$ & $1-3$ & $4-6$ & $7+$ & & & \\
\hline 1 & & $10(24.4 \%)$ & $17(41.4 \%)$ & $14(34.1 \%)$ & & 8.953 & 0.011* \\
\hline 2 & & $5(11.1 \%)$ & $33(73.3 \%)$ & $7(15.6 \%)$ & & & \\
\hline & $\begin{array}{l}\text { Employment } \\
\text { status }\end{array}$ & Employed & Unemployed & & & & \\
\hline 1 & & $15[36.6 \%]$ & $26[63.4 \%]$ & & & 0.100 & 0.752 \\
\hline 2 & & $15[33.3 \%]$ & $30[66.7 \%]$ & & & & \\
\hline
\end{tabular}

$1=$ Treatment Group $(n=41), 2=$ WL Control Group $(n=45)$ 

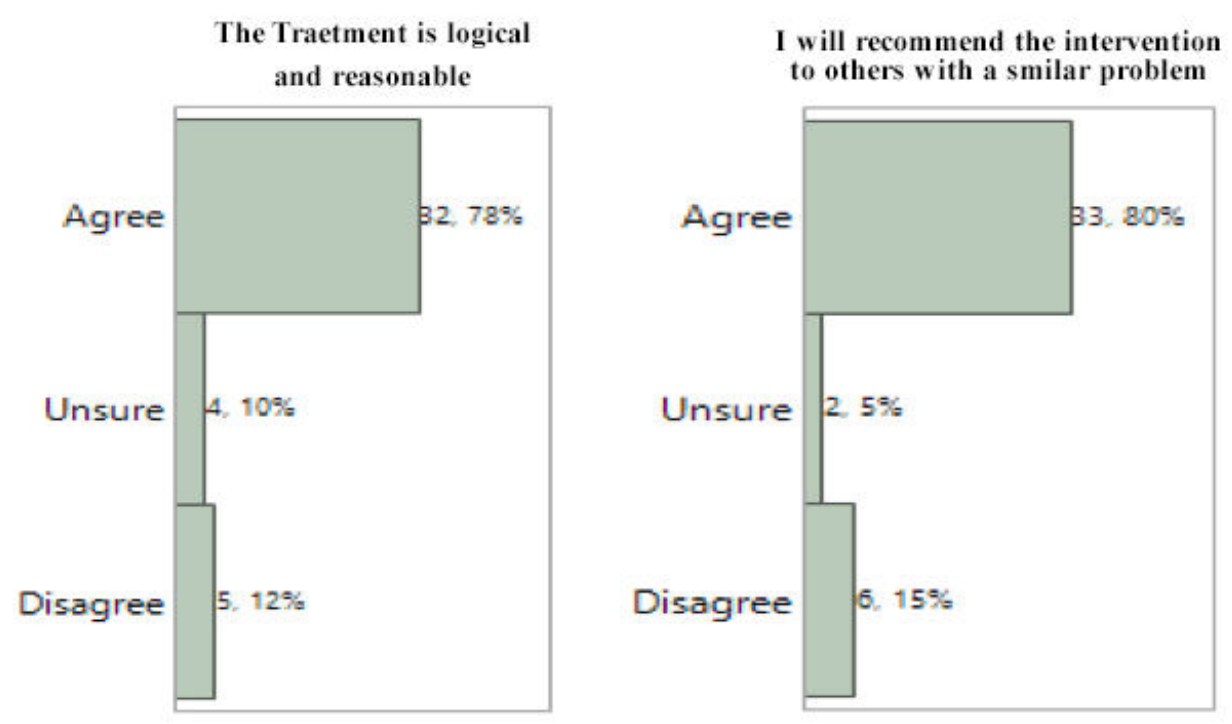

Fig.3. Analysis of responses on treatment credibility $(n=41)$.

the control group. The data analysis also reveals that $14(34.1 \%)$ participants reported having 7 and above number of children in the experimental group compared to $15.6 \%$ in the control group. Largely, the result reveals a significant difference exists in the number of children between the experimental and control group, $\chi^{2}=8.953, p=0.011$. There is no significant difference in the rate of employment between participants in the treatment group and the waitlist control group, $\chi^{2}=0.100, p=0.752$.

An assessment of the treatment credibility shows that there is a significant difference in the participant's response on whether the treatment is logical and reasonable, $\chi 2=36.926, p<0.001$. About $78 \%$ agreed the treatment is logical and reasonable as against $10 \%$ and $12 \%$ who are unsure and disagreed, respectively (Fig. 3). In addition, 80\% agreed they would recommend the intervention to others with a similar problem while $15 \%$ disagreed, with only $5 \%$ being unsure. The difference in responses on recommendation is significant, $\chi 2=41.609, p<0.001$. Fig. 4 is the analysis of covariance (ANCOVA) assumption test, which entails that the relationship between the covariate and dependent variable for each

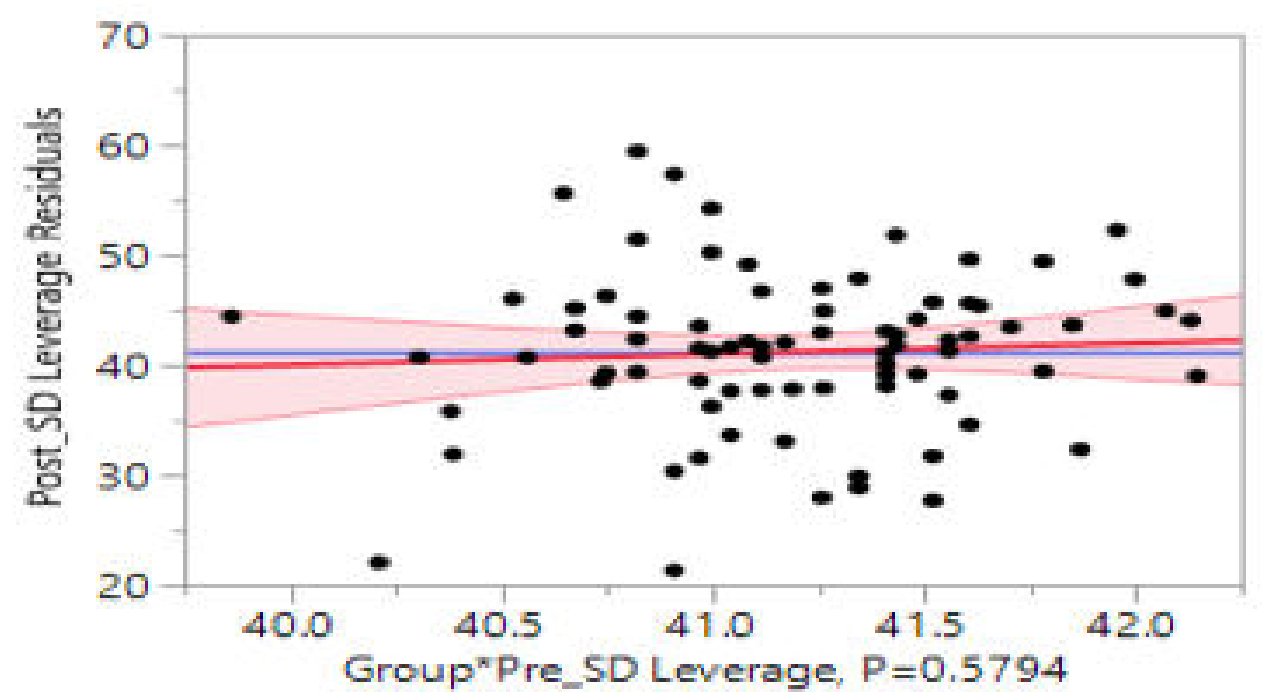

Fig.4. Leverage Plot for Pre_SD*Group testing the homogeneity of regression slope assumption. 
Table 3. Test of Lack of Fit for the model

\begin{tabular}{lcccccc}
\hline Source & DF & Sum of Squares & Mean Square & F Ratio & Prob $>$ F & Max RSq \\
\hline Lack of Fit & 36 & 2151.7927 & 59.7720 & 1.2053 & 0.2728 & 0.8106 \\
Pure Error & 46 & 2281.2500 & 49.5924 & & & \\
Total Error & 82 & 4433.0427 & & & & \\
\hline
\end{tabular}

of the groups is the same. Usually, similar slopes on the regression line for each group indicate this. Unequal slopes would indicate that there is an interaction between the covariate and the treatment. If there is an interaction then the results of ANCOVA could be deceptive [44, 45]. In this case, the interaction is not significant, $\mathrm{F}(1,82)=0.310, p=$ 0.579 , hence supporting the appropriateness of ANCOVA.
Table 3 is the lack of a fit report, which is the result of the effectiveness of cognitive reframing for widows. The essence of the test was to observe if the model fit the data collected appropriately. The lack of error analysis return sin significant outcome, $\mathrm{F}=$ $0.2728, p=0.8106$. This suggests that the model fits the data pretty well.

Table 4 showed the mean response and standard errors of participants' social disconnectedness before

Table 4. Pre and post-Least Sq Mean response of treatment Group and WL Control Group

\begin{tabular}{llcccc}
\hline Level & Group & Least Sq Mean & Std Error & Lower95\% & Upper 95\% \\
\hline Pre_SD & Treatment Group & 53.122 & 0.870 & 51.391 & 54.853 \\
& WL Control Group & 54.689 & 0.831 & 53.036 & 56.341 \\
\multirow{2}{*}{ Post_SD } & Treatment Group & 31.366 & 1.139 & 29.099 & 33.632 \\
& WL Control Group & 50.155 & 1.087 & 47.992 & 52.318 \\
\hline
\end{tabular}

Table 5. Analysis of variance showing model effects for groups

\begin{tabular}{lccccc}
\hline Source & DF & Sum of Squares & Mean Square & F Ratio & Prob $>$ F \\
\hline Model & 2 & 7595.855 & 3797.93 & 70.8412 & $<$ 0.0001* \\
Error & 83 & 4449.784 & 53.61 & & \\
C. Total & 85 & 12045.640 & & & \\
\hline
\end{tabular}

Summary of Fit: RSquare $=0.631$; RSquare Adj $=0.622$; Root Mean Square Error $=7.322$; Mean of Response $=$ 41.197; $\mathrm{N}=86$

and after the self-monitoring intervention. Mean precognitive reframing of social disconnectedness among treatment group was $53.122 \pm 0.870 ; 95 \% \mathrm{CI}=$ 51.391-54.853, but after the intervention, mean social disconnectedness reduced to $31.366 \pm 1.139 ; 95 \% \mathrm{CI}$ $=29.099-33.632$. The outcome showed a $40.95 \%$ remission in social disconnectedness behavior among the treated patient. The waitlist control group, on the other hand, had a mean social disconnectedness of $54.689 \pm 0.831 ; 95 \% \mathrm{CI}=53.036-56.341$ at the preintervention stage, but at the end of the study, WL control group mean response reduced to $50.155 \pm$
1.087; 95\% CI $=47.992-52.318$, implying a remission of only $8.29 \%$ after eight weeks.

Table 5 is the analysis of the covariance estimate, which was used to determine the overall treatment effects of group on social disconnectedness. The result revealed that overall, there is a significant effect of group $\mathrm{F}(2,83)=70.8412, p<0.0001$; $\mathrm{RMSE}=7.322$, suggesting that the two groups (experimental and waitlist control group) vary significantly in their response due to cognitive reframing administered. The outcome also reveals that the overall model was found to explain $63.1 \%$ variance. 
Table 6. Expanded estimates nominal factors expanded to all levels [treatment vs waitlist control]

\begin{tabular}{|c|c|c|c|c|c|c|}
\hline Term & Estimate & Std Error & t Ratio & $\operatorname{Prob}>|t|$ & $\begin{array}{l}\text { Lower } \\
95 \%\end{array}$ & $\begin{array}{r}\text { Upper } \\
95 \% \\
\end{array}$ \\
\hline Intercept & 45.669 & 7.766 & 5.88 & $<.0001 *$ & 30.222 & 61.115 \\
\hline Pre_SD & -0.091 & 0.143 & -0.64 & 0.5270 & -0.376 & 0.194 \\
\hline $\begin{array}{l}\text { Group [Treatment } \\
\text { Group] }\end{array}$ & -9.466 & 0.798 & -11.86 & $<.0001 *$ & -11.054 & -7.878 \\
\hline $\begin{array}{l}\text { Group [WL Control } \\
\text { Group] }\end{array}$ & 9.466 & 0.798 & 11.86 & $<.0001 *$ & 7.878 & 11.054 \\
\hline
\end{tabular}

Table 6 is an expanded estimates nominal factors expanded to all levels. It indicates that pretreatment outcome did not significantly influence the outcome of the study, $\beta=-0.091$ [95\% CI $=-0.376-0.194], \mathrm{t}=$ $-0.64, p=0.5270$. The treatment was significantly effective for the widows in the treatment group, $\beta=$ 9.466 [95\%CI $=-11.054--7.878], \mathrm{t}=-11.86, p<$ 0.0001 when compared to widows in the wait-list control group, $\beta=9.466$ [95\%CI $=7.878-11.054]$, $\mathrm{t}$ $=11.86, p<0.0001$. Subjectsin the intervention group reporteda higher reduction in their social disconnectedness behavior than did those in the waitlist control group. To have a graphical view of the variance in the effects of the intervention after eight weeks, a leverage plot for the group was presented (see Fig. 5).

\section{DISCUSSION}

There is a dearth in empirical research providing evidence of CR in decreasing socially disconnected behavior among widows. This attempted to examine if eight intervention using $\mathrm{CR}$ would be beneficial to widows who are socially disconnected. The result revealed that there is a significant decrease in social disconnectedness among widows after the intervention. The widows reported about $40.95 \%$ reduction when compared to their pre-test outcome. The reduction is significantly better than that of the waitlist control group who reported $8.29 \%$ decrease. Several results reported by previous studies corroborated the outcome of this study. In a study aimed to explore the feasibility and efficacy of a

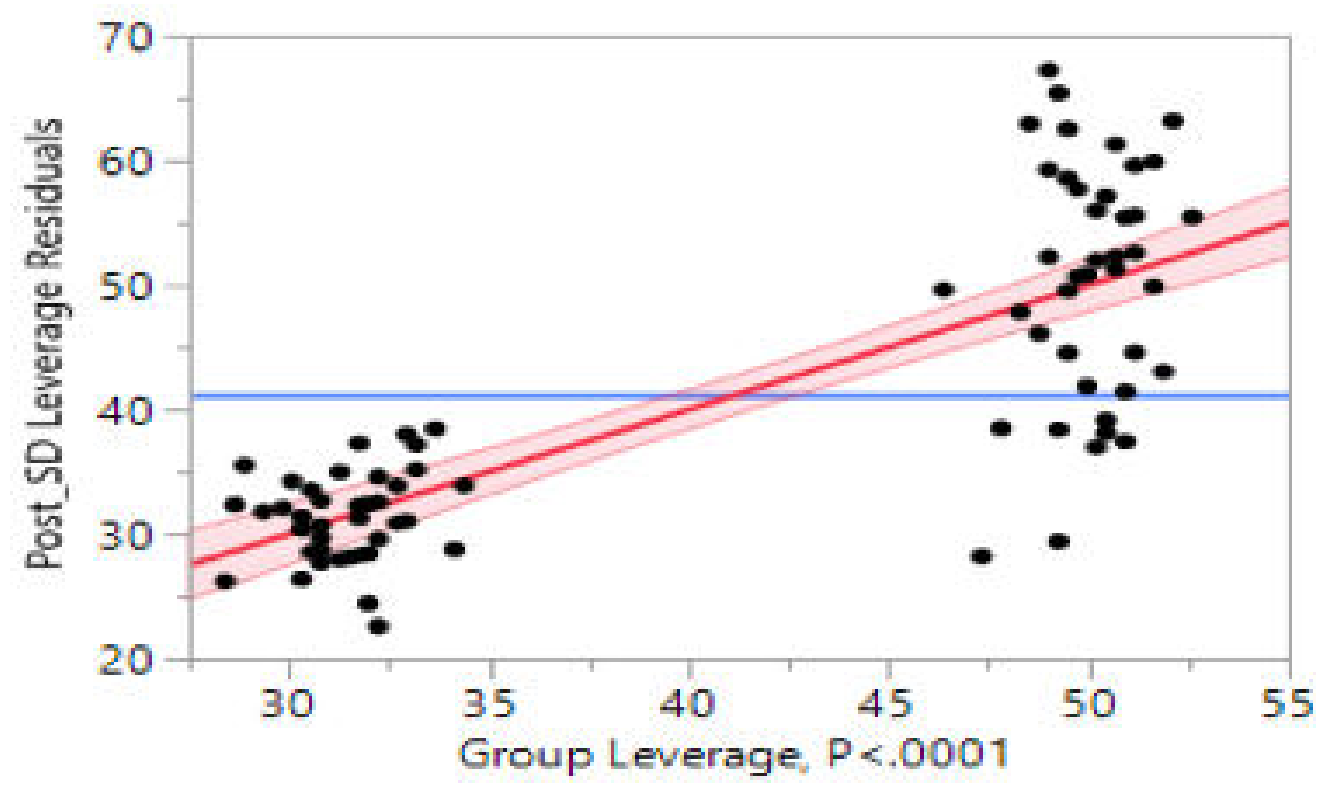

Fig.5. A leverage plot for group responsiveness to CR. 
manualized cognitive restructuring program for treating adolescents suffering from posttraumatic stress disorder (PTSD), Rosenberg, Jankowski, Fortuna, Rosenberg, and Mueser [43] reported that after weekly intervention for 12-16 weeks, there were statistically significant improvements in PTSD and depression. Treatment gains were maintained at 3month follow-up. Preliminary results suggest the feasibility of implementing a manualized cognitive restructuring program to treat PTSD in adolescents. Completers rated themselves as improved and satisfied at post-treatment and 3-month follow-up. Feedback from referring clinicians also indicated high satisfaction. In addition, Dublin [44] compared the effectiveness of Cognitive Restructuring versus Cognitive Defusion for Claustrophobic Anxiety and Avoidance. The result corroborates this outcome of this study as it shows that participants in the cognitive restructuring and cognitive defusion intervention conditions reported a significantly greater reduction in subjective anxiety at post-intervention assessment compared to those in the wait-list condition. Other findings reported that CBT for social anxiety disorder evidenced a medium to large effect size at immediate post-treatment as compared to control or waitlist treatments, with significant maintenance and even improvement of gains at follow-up [45]. Further, exposure, cognitive restructuring, social skills training, and both group/individual formats were equally efficacious [46], with superior performance over psychopharmacology in the long term [47].

\section{Limitations}

This present study has several limitations, though. Firstly, the study relied on self-reported measures of social disconnectedness instead of objective measure. Secondly, other physical and mental health problems not included or taken care of in this study may create asymmetries in widows' social relationship and limit their abilities and desires to develop and maintain healthy social relationships. Thirdly, the study only questioned the participant's level of education, number of children and employment status. Other socio demographic features like the number of siblings, the degree of closeness with siblings, the existence of close friends, the time of loss of a spouse, the number of years of widowhood, may all be related to losing reaction. The age of a widow partly accounts for some of the health disparities among widows [48]. Therefore, the fact that these variables were not looked at is a limitation of this study. Fourthly, using individual rather than group intervention may produce a better outcome as each participant would be given adequate attention. Fifthly, the used of a nonrandomized method in selecting the study sample may hinder the generalization of the findings of this study. Based on these limitations, therefore, causal connections implied by the findings of this study should be interpreted and taken with caution. It is hoped that further research would refine these concepts, address the study limitations to reveal causal mechanisms and help researchers and policymakers to better understand the health risks of social disconnectedness among widows and the application of a behavioral method to help widows to take back their lives [9].

\section{CONCLUSION}

The research presents an opportunity toward searching the relative effects of cognitive reframing on social disconnectedness among widows. The eight weeks group intervention method used in the study sample (widows) has suggested a successfully reduced socially disconnected behavior among widows by $40.95 \%$ compared to $8.29 \%$ for the waitlist control group. The treatment was reported as credible as $78 \%$ viewed it as logical and reasonable while $80 \%$ would recommend it to a friend or others with a similar problem. This study outcome may provide insight into the area of grieve support and encourage a healthy adjustment to widowhood.

\section{Conflict of interest}

The authors disclosed no conflict of interest during the preparation or publication of this manuscript.

\section{Financing}

The authors disclosed that they did not receive any grant from funding agencies in the public, commercial, or not-for-profit sectors during conduction or writing of this study. 


\section{REFERENCES}

1. The Loomba Foundation. The Global Widows Report 2015. A Global Overview of Deprivation Faced by Widows and Their Children. London. Loomba House. 2015.

2. World Data Atlas. Nigeria - Male adult mortality between age 15 and 60. 2019. Retrieved on 31/5/2019 from http://bit.ly/2QGiOUT

3. Uhlenberg P. International handbook of population aging. Dordrecht, the Netherlands: Springer, Netherlands. 2009.

4. Williams BR, Sawyer P, Allman RM. Wearing the garment of widowhood: variations in time since spousal loss among community-dwelling older adults. J Women Aging 2012;24:12639.

5. Li Y. Recovering from spousal bereavement in later life: does volunteer participation play a role? J Gerontol B Psychol Sci Soc Sci 2007;62:S257-66.

6. Aniruddha D. Spousal loss and health in late life: moving beyond emotional trauma. J Aging Health 2013;25:221-42.

7. Agrawal G, Arokiasamy P. Morbidity prevalence and health care utilization among older adults in India. J Appl Gerontol 2009;29:155-79.

8. Perkins JM, Lee H, James KS, Oh J, Krishna A, Heo J, et al. Marital status, widowhood duration, gender and health outcomes: A cross-sectional study among older adults in India. BMC Public Health 2016;16:1032.

9. Victor M. Social disconnectedness among widows in Nigeria: probing the effects of self-monitoring intervention. Eur Res J 2019;5:894-904.

10. Durojaye E. Woman, but not human: Widowhood Practices and Human Rights Violations in Nigeria. Int J Law Policy Family 2013;27:176-96.

11. Tamale S. Gender trauma in Africa: enhancing women's links to resources. J Afr Law 2004;48:50-61.

12. Ssenyonjo M. Culture and human rights of women in Africa: between light and shadow, J Afr Law 2007;51:39-67.

13. UchinoBN. Social support and health: a review of physiological processes potentially underlying links to disease outcomes. J Behav Med 2006;29:377-87.

14. Ryan AK, Willits FK. Family ties, physical health, and psychological well-being. J Aging Health 2007;19:907-20.

15. Teo AR, Choi H, Valenstein M. Social relationships and depression: ten-year follow-up from a nationally representative study. PLoS One 2013;8:e62396.

16. Kano R, Kondo N. Social Withdrawal of Young People, Psychosocial Background, Pathology and Treatment Aid. Iwasaki Gakujyutu Shuppan, Tokyo. 2000.

17. Victor CR, Scambler SJ, Shah S, Cook DG, Harris T, Rink E, et al. Has loneliness amongst older people increased? An investigation into variations between cohorts. Ageing Soc 2002;22:585-97.

18. Alpass FM, Neville S. Loneliness, health and depression in older males. Aging Mental Health 2003;7:212-6.

19. Afolayan GE. Widowhood practices and the rights of women.

The case of South-Western Nigeria. Erasmus: International Institute of Social Studies. 2011.

20. Jakobsson U, Hallberg, IR. Loneliness, fear, and quality of life among elderly in Sweden: a gender perspective. Aging Clin Exp Res 2005;17:494-501.

21. Cattan M, White M, Bond J, Learmouth A. Preventing social isolation and loneliness among older people: a systematic review of health promotion activities. Aging Soc 2005;25:41-67.

22. Findley RA. Interventions to reduce social isolation amongst older people: where is the evidence? Aging Soc 2003;23:647-58. 23. Motevalli S, Sulaiman T, Hamzah MSG, Garmjani MG, Kamaliyeh NG, Roslan S. The effects of cognitive restructuring intervention on state and trait anxiety among Iranian high school students. World Appl Sci J 2013;26:1499-1504.

24. Ghamari-Kivi H, Rafeie SH, Kiani AR. Effectiveness of cognitive restructuring and proper study skills in the reduction of test anxiety symptoms among students in Khalkhal, Iran. Am J Educ Res 2015;3:1230-6.

25. Adeusi SO, Gesinde AM, Alao AA, Adejumo GO, Adekeye OA. Differential effect of behavioural strategies on the management of conduct disorder among adolescents in correctional centres in Lagos State, Nigeria. Int J Psychol Couns 2015;7:63-8.

26. Hawton A, Green C, Dickens A, Richards S. Taylor R, Edwards R, et al. The impact of social isolation on the health status and health-related quality of life of older people. Qual Life Res 2011;20:57-67.

27. Victor M, Adeniyi EF. Cognitive behaviour techniques for primary insomnia: a non-randomized study among university students. CARD Int J Medl Sci Appl Biosci 2017;2:136-52.

28. Victor M, Balarabe M, Mohammed IA, Umaru Y. Cognitive behaviour and relaxation techniques: a comparative study among university students in Nigeria with primary insomnia. Arch Curr Res Int 2018;13:1-11.

29. Mark MM, Gamble C. Experiments, quasi-experiments andethics. In DM. Mertens PE. Ginsberg eds, Handbook of social research ethics. Thousand Oaks, CA: Sage. 2009.

30. Max M,Lynn J. Interactive textbook on clinical symptom research. The United States. Department of Health and Human Services. 2003.

31. Van Voohis CR, Morgan BL. Understanding power and rulesof thumb for determining sample sizes. Tutor Quant Methods Psychol 2007;3:43-50.

32. De Winter JFC. Using student's t test with extremely smallsample size. Practical Assessment, Research and Evaluation, 2015; 18 (10). Retrieved January 15, 2016, from http://pareonline.net/getvn.asp? $\mathrm{v}=18 \& \mathrm{n}=10$

33. Borkovec TD, Nau SD. Credibility of analogue therapy rationales. J Behav Ther Exp Psychiatry 1972;3:257-60.

34. Gellis LA, Arigo D, Elliott JC. Cognitive refocusing treatment for insomnia: a randomized controlled trial in university students. Behav Ther 2013;44:100-10.

35. Russell D. The UCLA Loneliness Scale (Version 3): Reliability, validity, and factor structure. J Pers Assess 1996;66;20-40.

36. Seeman TE. Health promoting effects of friends and family on health outcomes in older adults. Am J Health Prom 2000;14:362-70. 
37. Pressman SD, Cohen S, Miller, GE, Barkin A, Rabin BS, Treanor JJ. Loneliness, social network size and immune response to influenza vaccination in college freshmen. Health Psychol 2005;24:297-306.

38. Doane LD, Adam EK. Loneliness and cortisol: momentary, day to day, and trait associations. Psychoneuroendocrinology 2010;35:430-41.

39. Greenberger D, Westbrook D. Managing Depression. Oxford: Oxford Cognitive Therapy Centre. 2005.

40. Brosan L, Hogan H. An Introduction to coping with depression. London: Constable and Robinson Ltd. 2007.

41. Gilbert P. Overcoming Depression. London: Robinson. 2009. 42. Burns DD. The Feeling Good Handbook. Plumes: New York. 1999.

43. Rosenberg H, Jankowski MK, Fortuna L, Rosenberg SD. A pilot study of a cognitive restructuring program for treating posttraumatic disorders in adolescents. Psychol Trauma Theory
Res Pract Policy 2011;3:94-9.

44. Dublin RA. Cognitive Restructuring versus Cognitive Defusion for Claustrophobic Anxiety and Avoidance, 2012. Retrieved from http://gradworks.umi.com/35/13/3513681.html. 45. Gil PJM, Carrillo FXM, Meca JS. Effectiveness of cognitivebehavioral treatment in social phobia: a meta-analytic review. Psychology in Spain 2001;5;17-25.

46. Powers M, Sigmarsson SR, Emmelkamp MP. A meta-analytic review of psychological treatments for social anxiety disorder. Int J Cogn Ther 2008; 1:94-113.

47. Fedoroff I, Taylor S. Psychological and pharmacological treatments of social phobia: a meta-analysis. J Clin Psychopharmacol 2001;21:311-24.

48. Choi KH, Vasunilashorn S. Widowhood, age heterogamy, and health: the role of selection, marital quality and health behaviors. J Gerontol B Psychol Sci Soc Sci 2014;69:123-34. 